Working Paper

Series
॥IIIIFINRISK

National Centre of Competence in Research Financial Valuation and Risk Management

National Centre of Competence in Research

Financial Valuation and Risk Management

Working Paper No. 247

\title{
Does Prospect Theory Explain the Disposition Effect?
}

\section{Thorsten Hens}

\author{
Martin Vcek
}

First version: J uly 2005

Current version: September 2009

This research has been carried out within the NCCR FINRISK project on

"Evolution and Foundations of Financial Markets" 


\title{
Does Prospect Theory Explain the Disposition Effect?*
}

\author{
Thorsten Hens ${ }^{\mathrm{a}, \mathrm{b}} \quad$ Martin Vlcek ${ }^{\mathrm{a}}$
}

September 7, 2009

\begin{abstract}
The disposition effect is the observation that investors tend to realize gains more than losses. This behavior is puzzling, because it cannot be explained by traditional finance theories. A standard explanation of the disposition effect refers to prospect theory and, in particular, to the asymmetric risk aversion, according to which investors are risk-averse when faced with gains and risk-seeking when faced with losses. We show that for reasonable parameter values, the disposition effect cannot, however, be explained by prospect theory. The reason is that those investors who sell winning stocks and hold losing assets would not have invested in stocks in the first place. That is to say, the standard prospect theory argument is sound ex-post, assuming that the investment occurred, but not ex-ante, requiring also that the investment has to be made in the first place.
\end{abstract}

Keywords: Disposition effect, prospect theory, portfolio theory

JEL classification: D01, D14, D81,G11

${ }^{*}$ We appreciate the helpful comments of Jérôme Detemple, Darren Duxbury, Roy Kouwenberg, Andreas Krause, Dimitry Makarov and the participants of the 5th Swiss Doctoral Workshop in Finance, the EFMA 2006 Annual Conference, the IV Workshop LabSi on Behavioral Finance and the 9th Conference of the Swiss Society for Financial Market Research. Financial support by the University Research Priority Programme "Finance and Financial Markets" of the University of Zurich and the national center of competence in research "Financial Valuation and Risk Management" is gratefully acknowledged. The national centers in research are managed by the Swiss National Science Foundation on behalf of the federal authorities.

${ }^{a}$ Swiss Banking Institute and Swiss Finance Institute - Zurich, University of Zürich, Plattenstrasse 32, CH-8032 Zürich, Switzerland.

${ }^{\mathrm{b}}$ Norwegian School of Economics and Business Administration, Helleveien 30, N-5045, Bergen, Norway.

Email: thens@isb.uzh.ch,vlcek@isb.uzh.ch 


\title{
Does Prospect Theory Explain the Disposition Effect?
}

\author{
September 2008
}

\begin{abstract}
The disposition effect is the observation that investors tend to realize gains more than losses. This behavior is puzzling, because it cannot be explained by traditional finance theories. A standard explanation of the disposition effect refers to prospect theory and, in particular, to the asymmetric risk aversion, according to which investors are risk-averse when faced with gains and risk-seeking when faced with losses. We show that for reasonable parameter values, the disposition effect cannot, however, be explained by prospect theory. The reason is that those investors who sell winning stocks and hold losing assets would not have invested in stocks in the first place. That is to say, the standard prospect theory argument is sound ex-post, assuming that the investment occurred, but not ex-ante, requiring also that the investment has to be made in the first place.
\end{abstract}

Keywords: Disposition effect, prospect theory, portfolio theory

JEL classification: D01, D14, D81,G11 


\section{Introduction}

Despite the great success of the behavioral finance literature to explain the behavior of investors, the disposition effect remains one of the most striking and still unexplained phenomenons.

The disposition effect is the observation that investors tend to sell winning stocks and hold losing stocks. This observation has been made by a series of authors, including Shefrin and Statman (1985), Odean (1998), Weber and Camerer (1998), Heath, Huddart, and Lang (1999), Locke and Mann (2001), Grinblatt and Keloharju (2000), Grinblatt and Keloharju (2001), Ranguelova (2002), Shumway and Wu (2007) and Kaustia (2009).

Selling winners and keeping losers, as such, is perfectly compatible with complete rationality. A well known result, going back to Samuelson (1969) and Merton (1969), is that an expected utility maximizer, with constant relative risk aversion, rebalances a fixed-mix portfolio strategy in a setting where the investment opportunity set is constant. Therefore, when a security's price rises (falls), he decreases (increases) his investment in that security to rebalance to constant weights. However, as Odean (1998) has shown, investors are reluctant to sell losers, even when controlling for rebalancing. Hence the puzzling aspect of the disposition effect is the observation that investors show a more aggressive contrarian behavior than following the fixed-mix rule. This observation is all the more striking, because Odean (1998) shows that the prices of the winner stocks, which investors have sold, keep on rising, whereas the prices of the loser stocks, which investors have not sold, keep on falling. Hence, investors would have earned more money, had they behaved differently. Private information, as a potential explanation for the disposition effect, can therefore be excluded. Furthermore, Odean (1998) rejects other possible explanations, such as taxes and transaction costs.

Since the explanations based on traditional theories cannot be sustained, the above-mentioned authors propose behavioral explanations for the disposition effect. These are either based on perception or on valuation.

The perception argument is that investors (erroneously) believe in mean reverting asset prices, i.e. they believe that today's losers will outperform today's winners, and that today's winners are tomorrow's losers. Based on such beliefs, investors sell winners and hold losers. While this sounds like a valid explanation, in an interesting laboratory experiment Weber and Camerer (1998) reject the hypothesis that disposition behavior is due to the belief in 
mean-reverting stock prices.

The valuation argument refers to two of the main features of prospect theory. First, according to prospect theory, see Kahneman and Tversky (1979), investors evaluate outcomes relative to a reference point which, in the context of stock investments, is typically the purchasing price. Second, they behave as if evaluating the decision consequences on an S-shaped value function, which is concave for gains and convex for losses. This reflects risk aversion in the gain region and risk-seeking in the loss region. The standard behavioral finance explanation for the disposition effect is that a gain (loss) moves the investor to the risk-averse (seeking) part of the value function, so that he is inclined to reduce (increase) his position in the risky assets accordingly. Therefore, the disposition effect is commonly seen as an important implication of applying prospect theory to investment decisions and securities trading.

However, this standard explanation for why investors sell winners and hold losers has not yet been proved analytically. Also in this explanation, it is generally assumed that the investor has bought the risky stock, and thus the issue of whether the investor will decide to end up in a situation where the disposition effect may occur is ignored. Hence, this standard argument is, in fact, an ex-post argument that corresponds to a liquidation situation, as analyzed by Kyle, Ou-Yang, and Xiong (2003).

In our paper, we consider a model with two consecutive portfolio choices in a stylized financial market, where the investor's preferences are described by prospect theory, as suggested by Kahneman and Tversky (1979) and Tversky and Kahneman (1992). We investigate the investor's risk-taking behavior following a rise, respectively a fall, in the price of the risky asset. After analyzing the standard argument, i.e. ex-post disposition behavior, we focus on a more complete definition of disposition behavior, which we call ex-ante disposition behavior, where, besides requiring investors to sell winners and to hold losers, we explicitly require them to buy the stock in the first period. In both settings we however assume that investors are myopically planning ahead for one period only. Hence the ex-ante disposition effect would occur if the investor buys the asset in the first period - without considering changing his asset position in the next period and then when he makes a gain (loss) he happens to sell (hold) the asset. Alternatively, as Barberis and Xiong (2009) do, one could assume inter-temporal optimization and have the investor anticipate his next period actions conditional on the future states of the world. We think this clever intertemporal optimization is at odds with 
the assumption that agents have behavioral preferences as in prospect theory. Also, in that case the ex-ante disposition effect occurs for an optimization problem with a two period horizon while the ex-post disposition effect occurs on a one period horizon. As Benartzi and Thaler (1995) have shown such a comparison would be strongly influenced by a horizon effect called "myopic loss aversion", i.e. by the fact that loss averse investors would be inclined to invest in the risky asset when their horizon is two periods but not when it is only one period. Therefore, we have chosen to compare myopic optimization problems in the ex-ante and in the ex-post setting ${ }^{1}$.

Our first point of interest is the second period behavior of the investor, conditional on the stock price movement in the first period. Assuming that the investor is endowed with the stock in the first period, we call him an ex-post disposition investor if he sells the stock after a gain and holds onto it after a loss. We show how important aspects of prospect theory, in particular loss aversion and probability weighting, interact with asymmetric risk aversion. This analysis is of interest in itself, but it also lays the foundations for the inter-temporal argument. According to the inter-temporal view, we investigate the agent's behavior with a focus on ex-ante disposition behavior. We show interactions between loss aversion, decision weighting and asymmetric risk-taking.

Our findings are that investors are generally prone to the ex-post disposition effect, but seldom to the ex-ante disposition effect. The reason is that those investors who sell winning stocks too early and keep losing stocks too long would not have invested in stocks in the first place. The ex-post disposition effect tends to occur for lower coefficients of loss aversion, when the agent can undo the first period loss by investing in the risky asset. In the opposite case, i.e. when he is not able to undo the first period loss, the ex-post disposition effect tends to arise for more loss averse investors. The ex-ante disposition effect tends to arise for lower coefficients of loss aversion. Our results are robust to a large number of modifications and extensions of our model.

So, even when explicitly considering the asymmetric risk-taking behavior of agents, a standard explanation for disposition behavior, investors are not prone to the disposition effect. We conclude that prospect theory can indeed

\footnotetext{
${ }^{1}$ Nevertheless we checked whether this assumption would drive our negative result that prospect theory cannot explain the disposition effect. But, in line with Barberis and Xiong (2009), we find that this is not the case. See section 4.2 for further details.
} 
explain ex-post disposition behavior, but not ex-ante disposition behavior.

Many previous studies link the disposition effect to the standard argument described above, using intuitive reasoning. To our knowledge, only a few other papers formally analyze the relation between prospect theory and the disposition effect. In independent work, Barberis and Xiong (2009) investigate the trading behavior of investors with prospect theory preferences. Their analysis leads them to question, as we do, whether prospect theory predicts a disposition effect.

In contrast to our contribution, these authors consider an intertemporal decision model in which the investor optimizes over multiple periods. Since by intertemporal optimization the ex-post decision is anticipated ex-ante, if the disposition effects occurs in this setting it is the ex-ante disposition effect. Barberis and Xiong (2009) find that the investor realizes gains more than losses. They do not benchmark this finding against the traditional finance rule to follow a fixed-mix strategy.

Also, in comparison to Barberis and Xiong (2009), our contribution shows more details concerning the effects of the prospect theory preference parameters and the different return combinations on investment behavior. Further, they do not consider the impact of probability weighting. Overall, Barberis and Xiong (2009) and our paper provide two complimentary views on the disposition effect that deepen the understanding of this important empirical and experimental finding.

Besides Barberis and Xiong (2009) three more papers are worthwhile mentioning. Gomes (2005) studies the two-period portfolio problem of an investor with preferences that are related to, but different from, prospect theory. Specifically, for losses below some reference point he replaces the convex section of the value function with a concave segment. Other articles, which analyze the behavior of investors with prospect utility in general, as e.g. Berkelaar, Kouwenberg, and Post (2004) or Barberis and Santos (2001), abstract from probability weighting. Moreover, Barberis and Santos (2001) use a piecewise linear value function and Berkelaar, Kouwenberg, and Post (2004) consider a model in continuous time which generates the disposition effect even though in continuous time allows to concavify the value function. Summarizing, the disposition effect is not thoroughly understood in the literature and our paper contributes some aspects that are complimentary to the existing literature.

The rest of the paper is organized as follows. In the next section, we give a precise description of the framework. In section 3 , we analyze the ex- 
post behavior of a prospect theory investor and then we consider the intertemporal point of view. In the last two sections, we offer further discussion of our results and draw conclusions.

\section{The Model}

The structure of our model and the assumptions we make are justified by the necessity of a descriptive model, due to the fact that we want to explain a real world phenomenon. Furthermore, Feng and Seasholes (2005) show that the less sophisticated investors are, and the less trading experience they have, the more they are prone to the disposition effect. Therefore, we model the myopic portfolio choice of a small individual investor. To do so, we present a two period model for portfolio choice in a stylized financial market, where the investor's preferences are described by prospect theory, as suggested by Kahneman and Tversky (1979) and Tversky and Kahneman (1992). After describing the financial market and the agent's preferences, we derive the investor's optimization problem and the conditions under which the (ex-post) disposition effect arises.

In our framework, there is a financial market in which two assets are traded: A risk-free asset, also referred to as the bond, and a risky asset, also referred to as the stock. ${ }^{2}$ The evolution of the stock prices is described by a binomial process, so that at the end of the following period there are two possible states. If the stock price rises, we call the corresponding state the up state; the other state is called the down state. In the up state, which is realized with probability $p$, the risky investment yields a gross return $R_{U}$. Note that $0<p<1$. In the down state, arising with probability $1-p$, it yields $R_{D}$. The risk-free bond yields a sure gross return of $R_{f}$. We assume that the time value of money is positive, i.e. that interest rates are nonnegative. Absence of arbitrage requires that $R_{U}>R_{f}>R_{D}$. For the sake of simplicity, and without loss of generality, we further assume that $R_{D}<1$. To prevent negative stock prices, we assume $R_{D} \geq 0$. These assumptions about the financial market are summarized in the following inequality: $R_{U}>R_{f} \geq$ $1>R_{D} \geq 0$. All the parameters are assumed to be constant over time.

\footnotetext{
${ }^{2}$ The assumption that only one stock is relevant for the portfolio decision can be justified by mental accounting, an element in the standard argument. Mental accounting refers to the concept that individuals divide their assets into separate and non-transferable portions.
} 
The preferences of the investor are based on changes in wealth and are described by prospect theory. We assume that the investor owns an initial endowment, $W_{0}$, and that he has no other income. As we model a small individual investor, we assume that short selling is not allowed. Furthermore, we assume that the investor acts myopically ${ }^{3}$, and that the reference point he uses to measure his gains and losses is his initial wealth.

According to prospect theory, the overall value of a prospect is given by the sum of the subjective values of the outcomes weighted by the agent's decision weights associated with the probability of the outcome. The overall value of a prospect yielding gain $x$ with probability $p$, and loss $y$ with probability $1-p$, is given by: $V(x, p ; y, 1-p)=w(p) v(x)+w(1-p) v(y)$. The decision weights $w$ measure the impact of events on the desirability of prospects. According to Tversky and Kahneman (1992), the decision weights take the following form

$$
w(p)=\frac{p^{\gamma}}{\left(p^{\gamma}+(1-p)^{\gamma}\right)^{\frac{1}{\gamma}}}, \text { for some } 0 \leq \gamma \leq 1
$$

The value function $v$ assigns to each outcome $x$ a number $v(x)$, which reflects the subjective value of that outcome. The key features of prospect theory are that outcomes are coded into gains and losses, that losses hurt more than gains and that risk-taking behavior differs for gains and losses. Based on empirical evidence, Tversky and Kahneman (1992) proposed a two part power function

$$
v(x)=\left\{\begin{array}{ll}
x^{\alpha} & \text { if } x \geq 0 \\
-\beta(-x)^{\alpha} & \text { if } x<0
\end{array} .\right.
$$

The parameter $\beta$ is the coefficient of loss aversion and reflects the fact that losses hurt more than equivalent gains, which is true for all $\beta>1$. Using data from their experiments, the authors estimated $\beta$ to be equal to 2.25 . The coefficient $\alpha$ measures the agent's risk aversion and takes on values between zero and one. The authors estimated $\alpha$ to be equal to 0.88 . Observe that, in the domain of gains, i.e. $x \geq 0$, the value function is concave, implying that the agent is risk-averse, whereas in the domain of losses the function is

\footnotetext{
${ }^{3}$ Assuming myopic behavior for individual investors is appropriate for a descriptive model. It is consistent with the concept of narrow framing, i.e. the observation that individuals focus on the immediate future.
} 
convex, i.e. the investor prefers to gamble instead of facing a sure loss. We assume that all parameters are constant over time.

The investor's portfolio decision consists of allocating his wealth to the two assets traded in the financial market. In state $S$, he maximizes his utility by allocating a fraction of his wealth $\lambda_{S}$ in the risky asset and $1-\lambda_{S}$ in the risk-free asset.

In $t=0$, the investor owns his initial wealth $W_{0}$. With probability $p$, the stock price goes up and the good state is realized. In this case, the investor's wealth is $W_{U}{ }^{4}$ The investor's wealth position in the up state equals his initial wealth multiplied by the portfolio return. The portfolio return depends on the returns offered by the traded securities and on the investor's portfolio decision, i.e. the fraction of wealth invested in the risky asset, $\lambda_{0}$. The bad state is realized with probability $1-p$ and the stock price depreciates. The agent's wealth position is $W_{D}$.

As we assume in our model that all the parameters are constant over time, the setting in the second period has the same structure as in the first period. After the investor has made his first period investment decision, the state of nature in $t=1$ is realized. The market parameters, the investment decision $\lambda_{0}$ and the realized state of nature determine the agent's wealth in $t=1$. In the second period, the investor allocates his wealth from $t=1$ to the two assets traded in the financial market. The investor's wealth position in $t=2$ equals his position in $t=1$ multiplied by the return of his portfolio in the second period. The evolution of the investor's wealth, $W_{S}$, is depicted in Figure 1.

In each state, the myopic investor solves the optimization problem

$$
\max _{1 \geq \lambda_{S} \geq 0} V\left(\lambda_{S}\right)
$$

where

$$
\begin{aligned}
V\left(\lambda_{S}\right)= & w(p) v\left(W_{S}\left(\lambda_{S} R_{U}+\left(1-\lambda_{S}\right) R_{f}\right)-W_{0}\right) \\
& +w(1-p) v\left(W_{S}\left(\lambda_{S} R_{D}+\left(1-\lambda_{S}\right) R_{f}\right)-W_{0}\right)
\end{aligned}
$$

$w(p)$ is defined in (1), $v(x)$ in (2) and $S=0, U, D$.

The disposition effect arises whenever $\lambda_{D}>\lambda_{0}>\lambda_{U}$. We require the inequalities to be strict to make a clear distinction between disposition be-

\footnotetext{
${ }^{4}$ When indexing a variable in a particular state, we simply use the unambiguous short cut $U$, for the up state in $t=1, D$ for the down state in $t=1$, and likewise for $t=2$. When we refer to a point in time, i.e. no particular state, we index variables with $t=0,1,2$.
} 


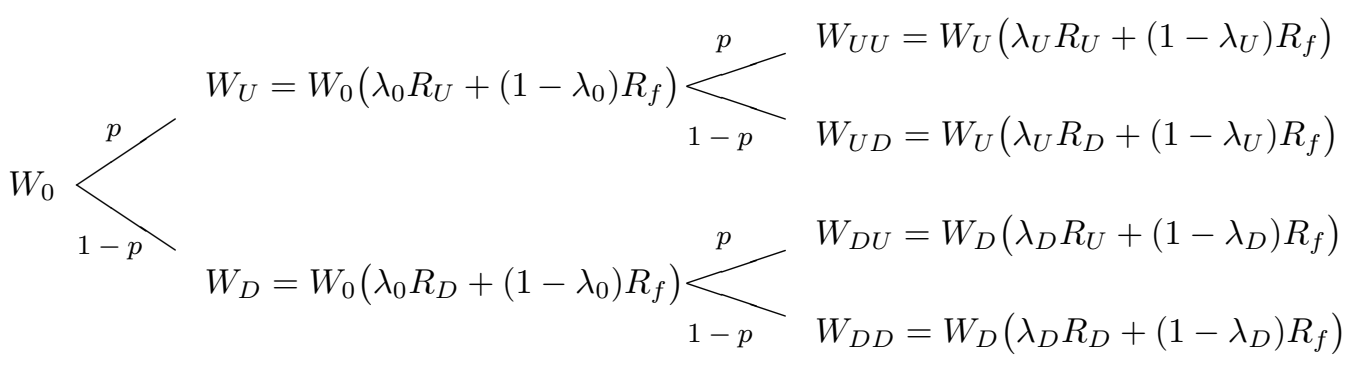

Figure 1: Evolution of the Investor's Wealth.

havior and a fixed-mixed investment strategy, as chosen by an expected utility maximizer with constant relative risk aversion. ${ }^{5}$

The condition for the occurrence of the disposition effect is computationally not tractable. ${ }^{6}$ To gain some insight into the solution, we restrict the fraction of wealth invested in the risky asset to either zero or one, which implies that the agent either chooses to invest fully, or not at all, in the risky asset. After having understood this more tractable case, we come back to the general case introduced above.

If, in $S=0$, the expected utility from holding the risky asset exceeds the utility from investing in the risk-free bond, the agent will invest in stocks. Otherwise, the agent prefers to invest his entire wealth in the risk-free bond. Hence, the agent invests his entire wealth in the risky asset whenever $V\left(\lambda_{0}=\right.$ 1) $>V\left(\lambda_{0}=0\right)$, or

$$
w(p)\left(R_{U}-1\right)^{\alpha}-w(1-p) \beta\left(1-R_{D}\right)^{\alpha}>\left(R_{f}-1\right)^{\alpha} .
$$

Next, we state the corresponding conditions for the other states. Note that, in $S=0$, when the investor chooses to invest in the stock, he experiences a gain whenever the stock price rises and he experiences a loss whenever the stock price falls. However, in $t=1$, we have to distinguish between different cases, which imply different possible portfolio performances in terms of gains and losses, and which in turn imply different valuations. The cases depend

\footnotetext{
${ }^{5}$ Note that, assuming that the investor updates his reference point would imply that he chooses a fixed-mix strategy too. Therefore we assume that he measures his gains and losses relative to his initial wealth.

${ }^{6}$ For a detailed discussion of the solution to the above optimization problem, we refer the reader to Vlcek (2005).
} 
on the downside risk of the risky asset. We distinguish assets with a low, medium and high downside risk. We define assets with a low downside risk, as assets with market parameters satisfying $R_{f} R_{D}>1$, and hence $R_{U} R_{D}>1$. When the parameters satisfy $R_{U} R_{D}>1$ and $R_{f} R_{D}<1$, we classify the assets as medium downside risk and otherwise, i.e. when $R_{U} R_{D}<1$, as high downside risk assets.

For an illustration, we use the annual data from 1927 to 2002 taken from French's data base ${ }^{7}$ and find the following classifications in terms of downside risk: assuming a risk-free rate of 5\%, the Intermediate-Term Government bonds (ITG), the Treasury Bill Rate (from Ibbotson Associates) and the High-Minus-Low portfolios (HML) belong to the low downside risk-class, the value-weight return on all NYSE, AMEX, and NASDAQ stocks (from CRSP) portfolio (RM) to the medium downside risk class and the Small-Minus-Big portfolio (SMB) to the high downside risk-class.

For assets with a low downside risk, i.e. for the case where the market parameters satisfy $R_{U} R_{D}>1$ and $R_{f} R_{D}>1$, the agent, who invests his entire wealth in the risky asset in $S=U$, experiences a gain in both states at the end of the next period, and makes a sure gain if he invests in the risk-free bond. If the down state realized in the first period, the investor who buys the risky asset in $S=D$ may make a gain, if, after the bad state, the good state is realized, or he may make a loss after the realization of two consecutive down states. If he chooses to invest his wealth in the risk-free alternative, he makes a sure gain.

For assets with a medium downside risk, i.e. for the case where $R_{U} R_{D}>1$ and $R_{f} R_{D}<1$, the investor who, in $S=U$, invests his entire wealth in the risky asset, experiences a gain, independent of which state realizes in the second period. He makes a sure gain if he invests in the risk-free bond. If the down state realized in the first period, and the investor invests in the risky asset, he experiences a gain or a loss. If the investor chooses to invest all his wealth in the risk-free alternative, he makes a sure loss.

For assets with a high downside risk, $R_{U} R_{D}<1$ and $R_{f} R_{D}<1$, the investor, who buys the risky asset in $S=U$, may make a gain if, after the up state the good state realizes, or may make a loss if, after the up state, the down state realizes. He makes a sure gain if he invests in the risk-free bond. If the down state realizes, the agent experiences a loss, independently of his

\footnotetext{
${ }^{7}$ See http ://mba.tuck.dartmouth.edu/pages/faculty/ken.french/data_library.html and Fama and French (1993) for details.
} 


\begin{tabular}{ccc|cc|cc}
\hline & \multicolumn{2}{c|}{$R_{U} R_{D}>1, R_{f} R_{D}>1$} & \multicolumn{2}{|c|}{$R_{U} R_{D}>1, R_{f} R_{D}<1$} & \multicolumn{2}{|c}{$R_{U} R_{D}<1, R_{f} R_{D}<1$} \\
\cline { 2 - 7 } & $U$ & $D$ & $U$ & $D$ & $U$ & $D$ \\
\hline$\lambda_{U}=1$ & gain & gain & gain & gain & gain & loss \\
$\lambda_{U}=0$ & gain & gain & gain & gain & gain & gain \\
$\lambda_{D}=1$ & gain & loss & gain & loss & loss & loss \\
$\lambda_{D}=0$ & gain & gain & loss & loss & loss & loss \\
\hline
\end{tabular}

Table 1: Gains and Losses in $t=2$. Depending on the investment strategy $\lambda_{S}$, and the characteristics of the risky asset, different portfolio performances arise.

portfolio choice and which state realizes in the second period. We summarize the possible different cases and the consequences in Table 1.

Assuming the investor purchased the stock in $S=0$, then, after the stock price appreciated in the first period, in $S=U$, the condition that the agent invests in a risky asset with a low or medium downside risk is

$$
w(p)\left(R_{U} R_{U}-1\right)^{\alpha}+w(1-p)\left(R_{U} R_{D}-1\right)^{\alpha}>\left(R_{U} R_{f}-1\right)^{\alpha} .
$$

The agent prefers a stock which has a high downside risk to the risk-free bond whenever

$$
w(p)\left(R_{U} R_{U}-1\right)^{\alpha}-w(1-p) \beta\left(1-R_{U} R_{D}\right)^{\alpha}>\left(R_{U} R_{f}-1\right)^{\alpha} .
$$

Similarly, in $S=D$, the condition that the agent invests in the risky asset with a low downside risk is

$$
w(p)\left(R_{U} R_{D}-1\right)^{\alpha}-w(1-p) \beta\left(1-R_{D} R_{D}\right)^{\alpha}>\left(R_{f} R_{D}-1\right)^{\alpha}
$$

in the case where $R_{U} R_{D}>1$ and $R_{f} R_{D}<1$

$$
w(p)\left(R_{U} R_{D}-1\right)^{\alpha}-w(1-p) \beta\left(1-R_{D} R_{D}\right)^{\alpha}>-\beta\left(1-R_{f} R_{D}\right)^{\alpha},
$$

and for a stock with a high downside risk

$$
w(p)\left(1-R_{U} R_{D}\right)^{\alpha}+w(1-p) \beta\left(1-R_{D} R_{D}\right)^{\alpha}<\left(1-R_{f} R_{D}\right)^{\alpha} .
$$


In the setting described, the disposition effect is that situation where the agent invests in the risky asset in $S=0$, sells the asset after the price appreciates and keeps on holding the risky stock after its price drops. This means that we observe the disposition effect whenever $\lambda_{0}=1, \lambda_{U}=0$ and $\lambda_{D}=1$. Thus, the conditions for the disposition effect to occur are ${ }^{8}$ :

1. For stocks with a low downside risk:

$$
\begin{gathered}
w(p)\left(R_{U}-1\right)^{\alpha}-w(1-p) \beta\left(1-R_{D}\right)^{\alpha} \geq\left(R_{f}-1\right)^{\alpha}, \\
w(p)\left(R_{U} R_{U}-1\right)^{\alpha}+w(1-p)\left(R_{U} R_{D}-1\right)^{\alpha} \leq\left(R_{U} R_{f}-1\right)^{\alpha} \text { and } \\
w(p)\left(R_{U} R_{D}-1\right)^{\alpha}-w(1-p) \beta\left(1-R_{D} R_{D}\right)^{\alpha} \geq\left(R_{f} R_{D}-1\right)^{\alpha} .
\end{gathered}
$$

2. For stocks with a medium downside risk:

$$
\begin{gathered}
w(p)\left(R_{U}-1\right)^{\alpha}-w(1-p) \beta\left(1-R_{D}\right)^{\alpha} \geq\left(R_{f}-1\right)^{\alpha}, \\
w(p)\left(R_{U} R_{U}-1\right)^{\alpha}+w(1-p)\left(R_{U} R_{D}-1\right)^{\alpha} \leq\left(R_{U} R_{f}-1\right)^{\alpha} \text { and } \\
w(p)\left(R_{U} R_{D}-1\right)^{\alpha}-w(1-p) \beta\left(1-R_{D} R_{D}\right)^{\alpha} \geq-\beta\left(1-R_{f} R_{D}\right)^{\alpha} .
\end{gathered}
$$

3. For stocks with a high downside risk:

$$
\begin{gathered}
w(p)\left(R_{U}-1\right)^{\alpha}-w(1-p) \beta\left(1-R_{D}\right)^{\alpha} \geq\left(R_{f}-1\right)^{\alpha}, \\
w(p)\left(R_{U} R_{U}-1\right)^{\alpha}-w(1-p) \beta\left(1-R_{U} R_{D}\right)^{\alpha} \leq\left(R_{U} R_{f}-1\right)^{\alpha} \text { and } \\
w(p)\left(1-R_{U} R_{D}\right)^{\alpha}+w(1-p)\left(1-R_{D} R_{D}\right)^{\alpha} \leq\left(1-R_{f} R_{D}\right)^{\alpha} .
\end{gathered}
$$

In the following, we investigate these conditions. First, we analyze the conditions for the ex-post disposition effect, i.e. the condition that the investor prefers simultaneously to invest in the risk-free bond in $S=U$ and in the stock in $S=D$. We then take a more complete perspective and require the agent to prefer the stock in $S=0$, to prefer the bond in $S=U$ and to prefer the stock in $S=D$.

\footnotetext{
${ }^{8}$ We assume that when the investor is indifferent between the risky and the risk-free asset, he purchases the stock in $S=0$ and $S=D$, and he invests in the bond in $S=U$.
} 


\section{Results}

In this section, we present the results of our model. We first analyze the case where $\lambda_{S}$ is restricted to zero or one. This allows us to make definite statements about the conditions for the occurrence of the disposition effect and to provide intuition for the results. Then we provide numerical results for the case where the agent is free to choose any degree of investment.

In the restricted case, we first discuss the relationship between loss aversion and the (ex-post) disposition effect. Next, we take on the traditional view, where it is implicitly assumed that the investor already owns the risky stock, and analyze his behavior, given the stock price movement. Then we provide a more complete view and require for the disposition effect not only that the investor sells a winning asset and keeps a losing asset, but also that the agent decides to buy the risky stock in $S=0$.

Analyzing the conditions for the occurrence of the (ex-post) disposition effect (10)-(12) allows us to discuss the role of loss aversion. A first observation is that, if the market parameters satisfy the condition $R_{U} R_{D}>1$, and if the disposition effect arises for a $\beta_{1}>1$, then it arises for all $\beta_{2}$, where $\beta_{1}>\beta_{2}>1$. The intuition is that an investor who is less loss-averse more readily buys the risky stock in $S=0$ and $S=D$. Note that, since the agent does not face a loss in $S=U D$ when investing in the risky asset, the condition to sell the stock in $S=U$ is independent of loss aversion.

If the risky asset is less attractive, $R_{U} R_{D}<1$, then the agent makes a loss in $S=D U$ and $S=D D$, independently of his investment decision, so that the investment decision in $S=D$ is independent of loss aversion. On the other hand, in $S=U$, the investor faces a potential loss when holding the risky asset. Hence, the more loss-averse he is, the more he prefers the risk-free asset. Note that the effects of an increase in loss aversion go in opposite directions for in $S=0$ and $S=U$. In absolute terms, the effect is stronger in $S=0$, so that, if the disposition effect arises for a $\beta_{1}>1$, then it arises for all $\beta_{2}$, where $\beta_{1}>\beta_{2}>1$. Again, a lower loss aversion implies that the investor more readily invests in the risky asset in the first period.

From these statements, it follows that the ex-post disposition effect arises more often for lower coefficients of loss aversion and for attractive stocks, i.e. if $R_{U} R_{D}>1$, and for higher coefficients of loss aversion and unattractive stocks, i.e. if $R_{U} R_{D}<1$. 


\subsection{The Ex-post Disposition Effect}

In this section, we assume that the investor is endowed with the risky asset and analyze his portfolio decision, given a stock price movement.

The investment decision as described above depends on the parameters of the agent's preferences, $\alpha, \beta$ and $\gamma$, as well as the parameters of the financial market, i.e. the returns and the probabilities of the possible states. Since many different parameters are involved, we first look at certain special cases in order to isolate the different effects of the parameters. As we have seen above, a lower loss aversion coefficient $\beta$ favors the occurrence of the ex-post disposition effect whenever $R_{U} R_{D}>1$, and lowers it in the opposite case. In this section, we focus on the impacts of the parameter of the decision weighting function $\gamma$ and the coefficient of risk aversion $\alpha$. We assume that the investor is loss-averse, i.e. $\beta>1$.

To get more insights, we vary the two preference parameters in the following way: the parameter of the decision weighting function, $\gamma$, is either fixed at 1 , so that the investor weights the outcomes with the objective probabilities, or it is assumed to lie between 0 and 1, implying that the agent distorts probabilities. When the coefficient of risk aversion, $\alpha$, is fixed, it is kept constant either at 0 or at 1 . When $\alpha=0$, the value function is flat in both the gain and loss domains. This implies that, after an initial gain, an additional gain does not yield any further utility; similarly, after an initial loss, an additional loss does not hurt more. In this sense, we can say that, if $\alpha=0$, the investor is quite risk-averse in the domain of gains and quite risk-seeking in the domain of losses. The other case, where $\alpha=1$, implies a piece-wise linear value function and that the investor is risk-neutral in both the gain and loss domains. Note that, whenever a gain or a loss can occur, the value function is concave in the relevant domain. This follows from the kink at the origin, i.e. from loss aversion. Hence the investor is risk-averse. When not held constant, $\alpha$ is assumed to lie between 0 and 1 , consistent with empirical findings.

These variations yield six possible outcomes. The more restrictions we impose on the parameters, the more tractable the inequalities describing the agent's choices become. Allowing for more general parameter ranges often has the drawback that no analytical statements can be made, so that we have to provide numerical solutions.

Proposition 1 summarizes the results for those cases where analytical statements can be made. Detailed proof is to be found in the appendix. 
Proposition 1. The ex-post disposition effect

1. An investor who weights outcomes with their objective probabilities and is quite risk-averse in the domain of gains and quite risk-seeking in the domain of losses, i.e. $\gamma=1$ and $\alpha=0$, is prone to the ex-post disposition effect whenever $R_{f} R_{D}<1$.

2. An investor who is risk-neutral in the gain and loss domains and weights outcomes with their objective probabilities, i.e. $\gamma=1$ and $\alpha=1$, is prone to the ex-post disposition effect whenever $R_{U} R_{D}<1$ and $\phi_{4} \geq p \geq \phi_{1}$, where $\phi_{4}=\frac{R_{U} R_{f}-1+\beta\left(1-R_{U} R_{D}\right)}{R_{U} R_{U}-1+\beta\left(1-R_{U} R_{D}\right)}$ and $\phi_{1}=\frac{R_{f}-R_{D}}{R_{U}-R_{D}}$.

3. An investor who weights outcomes with the decision weights, as proposed by Tversky and Kahneman (1992), and who is quite risk-averse in the domain of gains and quite risk-seeking in the domain of losses, i.e. $0<\gamma<1$ and $\alpha=0$, is prone to the ex-post disposition effect whenever $R_{f} R_{D}<1$.

An investor who weights outcomes with the objective probabilities, and is quite risk-averse in the domain of gains and quite risk-seeking in the domain of losses, i.e. $\gamma=1$ and $\alpha=0$, is prone to the ex-post disposition effect whenever the risky asset has a medium or high downside risk, i.e. if $R_{f} R_{D}<$ 1. The reason is that, in $S=U$, the agent is in the gain zone and therefore quite risk-averse, i.e. he does not gain utility from further gains, so that he never prefers the risky stock. In $S=D$, the investor is in the loss zone and hence quite risk-seeking, so that he invests in the risky asset, because additional losses do not yield additional pain.

For risky assets with a low downside risk, $R_{f} R_{D}>1$, the ex-post disposition effect does not arise, because the investor has the opportunity to realize a sure gain by investing in the risk-free bond in $S=D$ and therefore prefers the risk-free bond. Note that these statements apply even when the investor is not loss-averse.

When $\gamma=1$ and $\alpha=1$, i.e. the investor is risk-neutral in the gain and loss domains, and weights outcomes with their objective probabilities, he is prone to the ex-post disposition effect whenever, after a first period loss, he cannot undo this loss, i.e. when $R_{U} R_{D}<1$, and the probability of the occurrence of the good state is bounded by $\phi_{4}$ from above and by $\phi_{1}$ from below. $\phi_{1}$ is the martingale probability for the stock price to rise.

An investor who weights outcomes with the decision weights, as proposed by Tversky and Kahneman (1992), and who is quite risk-averse in the domain 
of gains and quite risk-seeking in the domain of losses, i.e. when $0<\gamma<1$ and $\alpha=0$, is prone to the ex-post disposition effect whenever $R_{f} R_{D}<1$. The same reasoning applies as in the above situation, where $\gamma=1$ and $\alpha=0$. Note that, for an investor with $\alpha=0$, probability weighting has no impact on the occurrence of the ex-post disposition effect.

For other combinations of $\alpha$ and $\gamma$, no unambiguous conclusions can be drawn. Therefore, we provide a numerical analysis. We illustrate the occurrence of the ex-post disposition effect in Figure 2. The first three graphs show the combinations of returns of the risky asset, $R_{D}$ and $R_{U}$, for which the expost disposition effect arises for different values of $\alpha$ and $\gamma$. The last graph completes these results by showing the influence of $\alpha$ and $\beta$. The parameter combinations, where the ex-post disposition effect occurs, are marked in black, whereas the domains, where the conditions for the ex-post disposition effect are not satisfied, are marked in red.

For the numerical analysis, the value of the gross risk-free rate, $R_{f}$, is kept constant at 1.1 and the probability of the occurrence of the up state, $p$, is fixed at 0.5 . The values of $R_{D}$ vary between 0 and 1 and $R_{U}$ is varied between 1.1 and 2.1. ${ }^{9}$ For other values of $p$ and $R_{f}$, similar results are obtained. ${ }^{10}$ Except for those cases where we explicitly assume different parameter values, the loss aversion coefficient, $\beta$, is kept constant at 2.25 , the value of the coefficient for risk aversion, $\alpha$, equals 0.88 , and the parameter of the decision weights, $\gamma$, is set equal to 0.65 . These preference parameter values are consistent with the empirical findings of Tversky and Kahneman (1992). ${ }^{11}$

The top-left graph shows the situation for an investor who weights outcomes with the objective probabilities, i.e. $\gamma=1$, and who is risk-averse (seeking) in the gain (loss) domain, $0<\alpha<1$. We see that the ex-post disposition effect seldom occurs, only in about $12 \%$ of the cases. We observe it for moderate and low returns in the down state and high returns in the up state.

The top-right graph illustrates the situation where $0<\gamma<1$ and $\alpha=1$,

\footnotetext{
${ }^{9}$ The ranges were chosen in order to prevent violation of the no-arbitrage condition.

${ }^{10}$ One of these is the case where $R_{f}=1$. It implies that the investor's alternative to buying the stock is holding cash. Note that, in this case, $R_{f} R_{D}<1, \forall R_{D}$ and hence the first case, where $R_{U} R_{D}>1$ and $R_{f} R_{D}>1$, never arises. Therefore we analyze in our numerical result the general case where $R_{f}>1$.

${ }^{11}$ Tversky and Kahneman (1992) have estimated the value of $\gamma$ to be 0.61 if gains are involved and 0.69 if losses are involved. For simplicity, we take the same value for gains and losses and set $\gamma=0.65$. Again, for other parameter values, similar results are obtained.
} 

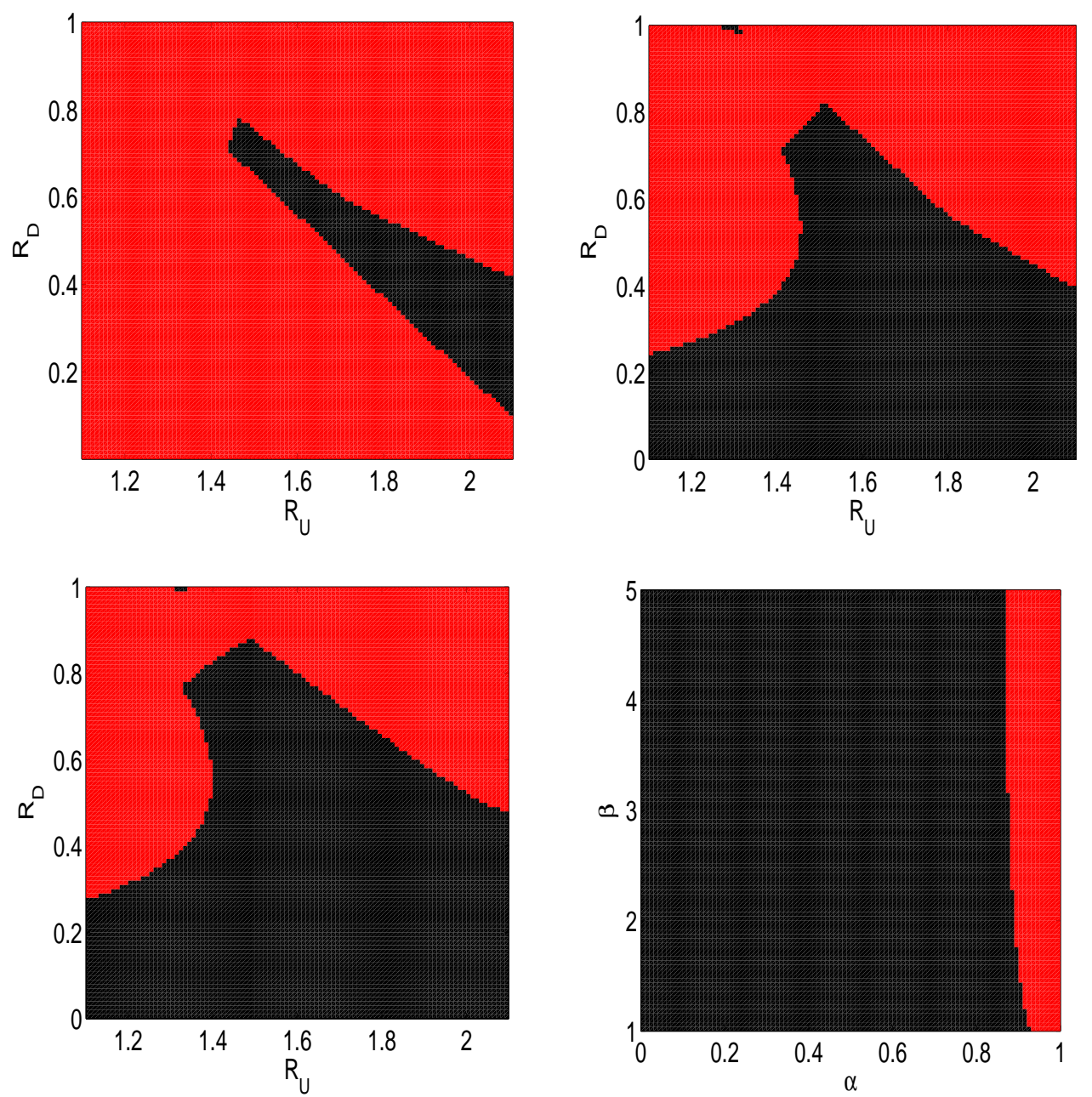

Figure 2: Occurrence of the Ex-Post Disposition Effect. The first three graphs show the combinations of returns $R_{D}$ and $R_{U}$, for which the expost disposition effect arises for different values of $\alpha$ and $\gamma$. The last graph completes these results by showing the influence of $\alpha$ and $\beta$. The parameter combinations, where the ex-post disposition effect occurs, are marked in black. Except for the cases where we explicitly assume different values, the following parameter values are used: $p=0.5, R_{D} \in[0,1], R_{f}=1.1$, $R_{U} \in[1.1,2.1], \alpha=0.88, \beta=2.25$, and $\gamma=0.65 . \lambda_{S}$ is restricted to zero or one. In $a$ ) the top-left graph $\gamma=1$ and $0<\alpha<1, b)$ the top-right graph $0<\gamma<1$ and $\alpha=1, c)$ the bottom-left graph $0<\gamma<1$ and $0<\alpha<1$ and in $d$ ) the bottom-right graph, we take a preference oriented view: $R_{U}=1.33$, $R_{D}=0.77, \alpha \in[0,1]$ and $\beta \in[1,5]$. 
i.e. an investor who distorts probabilities according to prospect theory and who is risk-neutral, both in the gain and loss domains. We observe that the ex-post disposition effect occurs frequently, in about $50 \%$ of the cases. It does so predominantly for moderate and low returns in the down state.

In the bottom-left graph, we show the most general case, i.e. the situation where $0<\gamma<1$ and $0<\alpha<1$. This is the case that corresponds to the empirical findings of Tversky and Kahneman (1992). We see that the ex-post disposition effect occurs frequently, in about $59 \%$ of the cases. We observe it for moderate and low returns in the down state, i.e. for risky assets with a high or medium downside risk. If we assume that the investor is not lossaverse, $\beta=1$, the ex-post disposition effect occurs in $61 \%$ of the cases (not shown in Figure 2).

To gain more insight on the different drivers of the ex-post disposition effect, we present the bottom-right graph. Here we take a preference oriented view and illustrate the occurrence of the ex-post disposition effect for different combinations of $\alpha$ and $\beta$; $\alpha$ ranges from 0 to 1 and $\beta$ from 1 to 5 . The market parameters are fixed for one of the cases where we observe the expost disposition effect in the general case, $0<\gamma<1$ and $0<\alpha<1$, above: $R_{U}=1.33, R_{D}=0.77, R_{f}=1.1$ and $p=0.5$. We observe that the ex-post disposition effect occurs for most of the parameter combinations. Although it arises slightly more often for lower $\beta$, our result, that the ex-post disposition effect occurs frequently, is robust to changes in the preference parameters. ${ }^{12}$

We summarize the results for the ex-post disposition effect in Table 2.

\subsection{The ex-ante Disposition Effect}

In this section, we take a step backward in time and impose the additional condition that, besides selling a winning stock and keeping a losing stock, the investor has to buy the stock in the first place. This means that the disposition effect arises whenever the requirements to simultaneously prefer the stock in $S=0$ and $S=D$ and to prefer the bond in $S=D$ are satisfied.

\footnotetext{
${ }^{12}$ Note that the case where the parameters are consistent with empirical findings, $\alpha=$ 0.88 and $\beta=2.25$, is close to the edge of the area, where the ex-post disposition effect arises. This follows from the fact that the return combination we have chosen for the preference parameter graph lies on the edge of the domain where the ex-post disposition effect occurs in the $R_{U}-R_{D}$ diagram (bottom-left). For other return combinations, that lie further in the black zone, in the $R_{U}-R_{D}$ diagram, the case, where $\alpha=0.88$ and $\beta=2.25$, is in the interior of the domain where the ex-post disposition effect occurs.
} 


\begin{tabular}{ccc}
\hline \hline & & Ex-Post Disposition Effect \\
\hline$\gamma=1$, & $\alpha=0$ & If $R_{f} R_{D}<1,(90 \%)$ \\
$\gamma=1$, & $\alpha=1$ & If $R_{U} R_{D}<1,(6 \%)$ \\
$\gamma=1$, & $0<\alpha<1$ & 0.1201 \\
$0<\gamma<1$, & $\alpha=0$ & If $R_{f} R_{D}<1,(90 \%)$ \\
$0<\gamma<1$, & $\alpha=1$ & 0.4997 \\
$0<\gamma<1, \quad 0<\alpha<1$ & 0.5896 \\
\hline
\end{tabular}

Table 2: Occurrence of the Ex-Post Disposition Effect. We quantify the occurrence of the ex-post disposition effect for the following parameter values: $p=0.5, R_{U} \in[1.1,2.1], R_{f}=1.1$ and $R_{D} \in[0,1]$. If no other parameter values are explicitly assumed, then $\alpha=0.88, \beta=2.25$, and $\gamma=0.65$. $\lambda_{S}$ is restricted to zero or one.

This makes the definition of the disposition effect more consistent. Since the conditions for the disposition effect in $t=1$ stay the same as for the ex-post disposition effect, we focus in this section on the first period condition.

As in the previous section, we first look at different special cases in order to isolate the effects of the parameters. We focus on the impacts of the parameter of the decision weighting function, $\gamma$, and the coefficient of risk aversion, $\alpha$. We assume that the investor is loss-averse.

We vary the two parameters, as in the previous section: the parameter of the decision weighting function, $\gamma$, is either fixed at 1 , so that the investor weights the outcomes with the objective probabilities, or it is assumed to be between 0 and 1 . When the coefficient of risk aversion, $\alpha$, is fixed, it is kept constant either at 0 or 1 . Otherwise, it is assumed to be between 0 and 1 . This yields six possible outcomes. The more restriction we impose on the preference parameters, the more tractable the inequalities describing the agents choices become. Allowing for more general parameter ranges often has the drawback that no analytical statements can be made, so that we have to provide numerical solutions.

Proposition 2 summarizes the results for the cases where analytical statements can be made. The detailed proof is to be found in the appendix.

Proposition 2. The ex-ante disposition effect

1. An investor, who weights outcomes with their objective probabilities, 
and is quite risk-averse in the domain of gains and quite risk-seeking in the domain of losses, i.e. $\gamma=1$ and $\alpha=0$, is never prone to the disposition effect.

2. An investor, who is risk-neutral in the gain and loss domains, and weights outcomes with their objective probabilities, i.e. $\gamma=1$ and $\alpha=$ 1 , is never prone to the disposition effect.

3. An investor who weights outcomes with the decision weights, as proposed by Tversky and Kahneman (1992), and who is quite risk-averse in the domain of gains and quite risk-seeking in the domain of losses, i.e. $0<\gamma<1$ and $\alpha=0$, is never prone to the disposition effect.

An investor, who weights outcomes with their objective probabilities, and who is quite risk-averse in the domain of gains and quite risk-seeking in the domain of losses, never invests in the risky asset, in $S=0$, as long as he is loss-averse. This implies that he is not prone to the disposition effect.

If the investor is risk-neutral in the gain and loss domains and weights outcomes with their objective probabilities, he is never prone to the disposition effect. The reason is that he either does not purchase the stock in $S=0$ or that, if he does, he never sells it after a gain.

An investor, who weights outcomes with the decision weights, as proposed by Tversky and Kahneman (1992), and who is quite risk-averse in the domain of gains and quite risk-seeking in the domain of losses, never invests in the risky asset in $S=0$, implying that he is not prone to the disposition effect. Note that, as was the case with the ex-post disposition effect, if $\alpha=0$, then the probability weighting has no impact on the occurrence of the disposition effect.

For the other combinations of $\alpha$ and $\gamma$, no unambiguous conclusions can be drawn. Hence, we provide a numerical analysis and illustrate the occurrence of the disposition effect in Figure 3; its structure is similar to that of Figure 2. The first three graphs show the combinations of returns of the risky asset, $R_{D}$ and $R_{U}$, for which the ex-post disposition effect arises for different values of $\alpha$ and $\gamma$. The last graph completes these results by showing the influence of $\alpha$ and $\beta$. The parameter combinations, where the disposition effect occurs, are marked in black.

The gross risk-free rate, $R_{f}$, is kept constant at 1.1, and the probability of the occurrence of the up state, $p$, is fixed at 0.5 . The values of $R_{D}$ vary between 0 and 1 and $R_{U}$ is varied between 1.1 and 2.1. For other values 

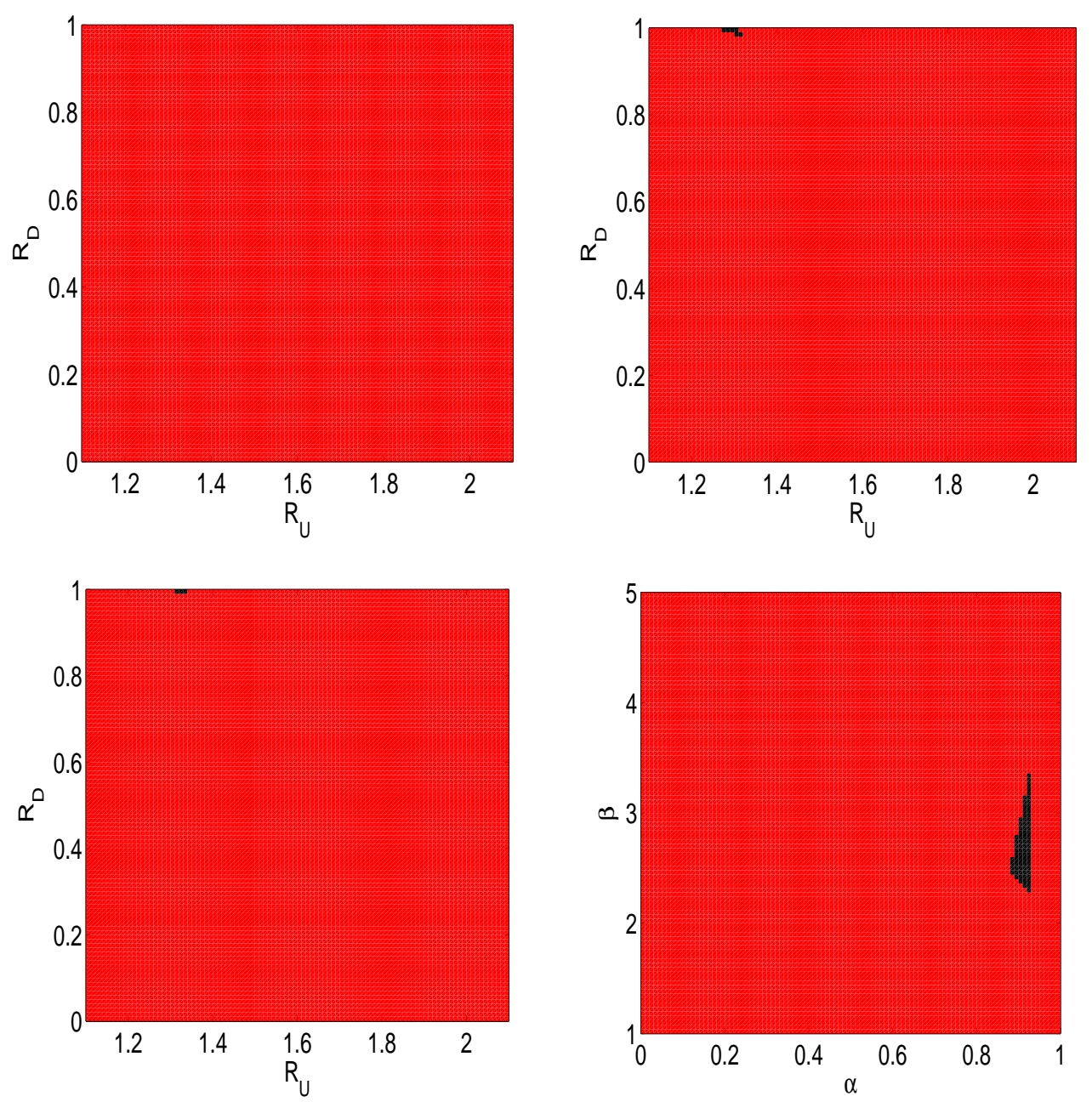

Figure 3: Occurrence of the Disposition Effect. The first three graphs show the combinations of returns $R_{D}$ and $R_{U}$, for when the disposition effect arises for different values of $\alpha$ and $\gamma$. The last graph completes these results by showing the influence of $\alpha$ and $\beta$. The parameter combinations, where the disposition effect occurs, are marked in black. Except for the cases where we explicitly assume different values, the following parameter values are used: $p=0.5, R_{D} \in[0,1], R_{f}=1.1, R_{U} \in[1.1,2.1], \alpha=0.88, \beta=2.25$, and $\gamma=0.65$. $\lambda_{S}$ is restricted to zero or one. In $a$ ) the top-left graph $\gamma=1$ and $0<\alpha<1, b)$ the top-right graph $0<\gamma<1$ and $\alpha=1, c)$ the bottom-left graph $0<\gamma<1$ and $0<\alpha<1$ and in $d$ ) the bottom-right graph, we take a preference oriented view: $R_{U}=1.33, R_{D}=0.77, \alpha \in[0,1]$ and $\beta \in[1,5]$. 
of $p$ and $R_{f}$, similar results are obtained. Except for those cases where we explicitly assume different values, the loss aversion coefficient, $\beta$, is kept constant at 2.25, the value of the coefficient for risk aversion, $\alpha$, equals 0.88 , and the parameter of the decision weights, $\gamma$, is set equal to 0.65 . These preference parameter values are consistent with the empirical findings of Tversky and Kahneman (1992).

The top-left graph shows the situation for an investor who weights outcomes with the objective probabilities, i.e. $\gamma=1$, and who is risk-averse (seeking) in the gain (loss) domain, $0<\alpha<1$. We observe that the disposition effect almost never occurs. In fact, overall, it occurs in less than $0.5 \%$ of the cases.

The top-right graph illustrates the situation where $0<\gamma<1$ and $\alpha=1$, i.e. an investor, who distorts probabilities according to prospect theory, and who is risk-neutral, both in the gain and loss domains. We observe that the disposition effect occurs very rarely, in less than $0.5 \%$ of the cases. We observe it for returns in the up state in the order of 1.3 and for very high returns in the down state. We can conclude that the disposition behavior of this investor is a unique case and does not occur in general.

In the bottom-left graph, we show the most general case, i.e. the situation where $0<\gamma<1$ and $0<\alpha<1$. This is the case that corresponds best to the empirical findings of Tversky and Kahneman (1992). We see that the disposition effect occurs very rarely, in less than $0.5 \%$ of the cases. We observe it for returns in the up state in the order of 1.3 and for very high returns in the down state. We can conclude that the disposition behavior for this agent is a unique case and does not occur in general. If we assume that the investor is not loss-averse, $\beta=1$, the disposition effect occurs in about $9 \%$ of the cases (not shown in Figure 2).

To gain more insight into the different drivers of the disposition effect, we present the bottom-right graph. Here we take a preference oriented view, and illustrate the occurrence of the ex-post disposition effect for different combinations of $\alpha$ and $\beta ; \alpha$ ranges from 0 to 1 and $\beta$ from 1 to 5 . The market parameters are fixed for one of the cases where we observed the disposition effect in the general case, where $0<\gamma<1$ and $0<\alpha<1$ above, i.e. $R_{U}=1.32, R_{D}=0.99, R_{f}=1.1$ and $p=0.5$. Again, we observe that the disposition effect occurs only for a very small part of the possible parameter combinations, and slightly more often for low $\beta$. Therefore, the fact that our model, in general, does not predict disposition behavior, is robust to changes in the preference parameters. 


\begin{tabular}{ccc}
\hline \hline & & Disposition Effect \\
\hline$\gamma=1$, & $\alpha=0$ & Never \\
$\gamma=1$, & $\alpha=1$ & Never \\
$\gamma=1$, & $0<\alpha<1$ & $9.8030 \mathrm{e}-005$ \\
$0<\gamma<1$, & $\alpha=0$ & Never \\
$0<\gamma<1$, & $\alpha=1$ & 0.0014 \\
$0<\gamma<1$, & $0<\alpha<1$ & $9.8047 \mathrm{e}-004$ \\
\hline
\end{tabular}

Table 3: Occurrence of the Ex-Ante Disposition Effect. We quantify the occurrence of the disposition effect for the following parameter values: $p=$ $0.5, R_{U} \in[1.1,2.1], R_{f}=1.1$ and $R_{D} \in[0,1]$. If no other parameter values are explicitly assumed, then $\alpha=0.88, \beta=2.25$, and $\gamma=0.65 . \quad \lambda_{S}$ is restricted to zero or one.

We summarize the results for the disposition effect in Table 3.

\subsection{Any Degree of Investment}

In order to generalize our results, we relax the restriction that the investor has to invest either fully or not at all. Since, in this case, the conditions for the occurrence of the disposition effect are computationally not tractable, we provide numerical results.

While we allow the investor to choose any degree of investment, we maintain all other assumptions; in particular, the one that short selling is not allowed. The disposition effect, i.e. the observation that investors sell winners and hold losers more aggressively than a fixed-mix strategy would imply, arises whenever $\lambda_{D}>\lambda_{0}>\lambda_{U}{ }^{13}$

As above, we quantify the occurrence of the disposition effect for different values of $\alpha, \gamma, R_{U}$ and $R_{D}$. The results, in Table 4 , were calculated for the following parameter values: $p=0.5, R_{U} \in[1.1,2.1], R_{f}=1.1$ and $R_{D} \in$ $[0,1]$. If no other parameter values are explicitly assumed, then $\alpha=0.88$,

\footnotetext{
${ }^{13}$ Whereas in the setting where $\lambda_{S}$ is restricted to either zero or one, the definition of ex-post disposition behavior is evident, it is not in the case where the investor is free to choose any degree of investment. Particularly, the assumption about the first period endowment is ambiguous. Since this quantity influences significantly the statements about the occurrence of the ex-post disposition effect, we will not provide such results.
} 


\begin{tabular}{ccc}
\hline \hline & & Disposition Effect \\
\hline$\gamma=1$, & $\alpha=0$ & 0.0000 \\
$\gamma=1$, & $\alpha=1$ & 0.0013 \\
$\gamma=1$, & $0<\alpha<1$ & 0.0000 \\
$0<\gamma<1$, & $\alpha=0$ & 0.0000 \\
$0<\gamma<1$, & $\alpha=1$ & $7.84242-004$ \\
$0<\gamma<1, \quad 0<\alpha<1$ & 0.0000 \\
\hline
\end{tabular}

Table 4: Occurrence of the Ex-Ante Disposition Effect for Any Degree of Investment. We quantify the occurrence of the disposition effect for the following parameter values: $p=0.5, R_{U} \in[1.1,2.1], R_{f}=1.1$ and $R_{D} \in$ $[0,1]$. If no other parameter values are explicitly assumed, then $\alpha=0.88$, $\beta=2.25$, and $\gamma=0.65$.

$\beta=2.25$, and $\gamma=0.65$.

The results show that, even when allowing for any degree of investment, the disposition effect practically does not occur, thus supporting the above results. If we assume that the investor is not loss-averse, $\beta=1$, the disposition effect occurs in less than $0.5 \%$ of the cases (not shown in Table 4).

In the case where $\lambda_{S}$ is restricted to be either zero or one, the argument is, that for parameter values where it is optimal to sell winners and to hold losers, it is not optimal to invest in the risky asset in the first period. In the case where the investor can choose any degree of investment, the analogous argument is that, whenever it is optimal to sell winners and to hold losers, it is not optimal to choose a $\lambda_{0}$, such that $\lambda_{D}>\lambda_{0}>\lambda_{U}$. In the next section, we discuss our results.

\section{Discussion}

In this section, we discuss the results, provide some robustness checks and an alternative explanation. Since the conditions for the occurrence of the disposition effect are more tractable in the case where $\lambda_{S}$ is restricted to 
zero or one, we mainly refer to this case. As the previous section has shown, this case also provides the intuition for the general case.

\subsection{Intuition}

We first discuss the role of loss aversion for those conditions where the (expost) disposition effect occurs. A general observation is that an investor, who is less loss-averse, more readily invests in the risky alternative. The less a potential loss hurts, the more he invests in the risky alternative. Where the conditions for the disposition effect are concerned, the consequences of an increase in loss aversion go in opposite directions for $S=0$ and $S=U$. In absolute terms, the effect is stronger in $S=0$, so that the disposition effect occurs more frequently for low coefficients of loss aversion.

If the investor cannot lose his first period gain when holding the risky stock in $S=U$, i.e. when $R_{U} R_{D}>1$, his decision in that node is independent of loss aversion. Therefore, a lower coefficient of loss aversion favors the occurrence of the ex-post disposition effect. In the opposite case, $R_{U} R_{D}<1$, the investor cannot undo a first period loss. Hence, a higher coefficient of loss aversion favors the ex-post disposition effect.

We summarize the impact of risk aversion, $\alpha$, and probability weighting, $\gamma$, in Tables 2 and 3. In some cases, we are able to make analytical statements. In other cases, we rely on numerical computations.

A first observation (see Table 2) is that the ex-post disposition effect occurs quite frequently. It occurs particularly frequently in the case where $\alpha=0$, i.e. where, after an initial gain (loss), an additional gain (loss) does not yield any further utility (pain). In this case, the investor sells winners and holds losers, unless he can undo a first period loss by investing in the risk-free alternative, i.e. $R_{f} R_{D}>1$.

In the cases where we can make analytical statements, our results clearly show that the ex-post disposition effect occurs when the risky asset has a high downside risk, i.e. for low values of $R_{D}$. In the other cases, we observe in Figure 2 that the ex-post disposition effect arises rather for low values of $R_{D}$, i.e. again when the risky asset has a high downside risk.

An investor, who owns a risky asset that has a high downside risk, is deep in the loss zone after a first period loss, i.e. in $S=D$. Therefore he is risk-seeking. This implies that he will prefer the risky alternative to the risk-free bond. Hence, he holds the losing stock. On the other hand, after a gain, the investor is in the gain zone. Holding the stock for another period 
will imply a possible loss at the end of the following period. Therefore he prefers the safe investment to the risky stock and therefore he sells winners. This preference is amplified by loss aversion.

Regarding probability weighting, we observe that, except for $\alpha=0$, the ex-post disposition effect occurs for lower values of $\gamma$. According to prospect theory, investors overweight small probabilities and underweight moderate and high probabilities. In the case where both states are equally likely, the investors underweight both outcomes. The more they underweight, i.e. the lower $\gamma$ is, the less attractive the risky alternative becomes. Therefore they sell winners. Moreover, under the condition that $R_{U} R_{D}<1$ and $R_{f} R_{D}<1$, even in $S=D$, decision weighting works in favor of the ex-post disposition effect. The reason is that it lowers the disutility from investing in the stock.

The conditions for the occurrence of the ex-ante disposition effect (see Table 3) are practically never satisfied, even in the cases where the ex-post disposition effect occurs for most of the parameter values. In the cases where we can make analytical statements, we prove that the ex-ante disposition effect never occurs. In the cases where we make numerical calculations, the occurrence of the disposition effect decreases considerably. This shows that investors, who behave like ex-post disposition investors, would not have invested in the risky asset in the first place.

The intuition behind this result is the following: as we have seen above, the ex-post conditions are satisfied for stocks with a high downside risk. However, the investor does not want to invest in such an asset in $S=0$. On the other hand, if the stock is attractive enough, and the investor chooses to buy it in $S=0$, then he will not sell it in $S=U$.

As we have seen above, the disposition effect occurs more often for low coefficients of loss aversion and hence the question arises, whether the standard prospect theory argument applies for loss-neutral investors. From above we know that the S-shaped value function is not sufficient to explain the disposition effect. Here we grasp the intuition for this result. For the sake of illustration we assume that interest rates are zero, i.e. $R_{f}=1$, that the initial endowment is zero, $W_{0}=0$, and that the investor weights outcomes with their objective probabilities, i.e. $\gamma=1 .^{14}$

Consider a stock that pays with equal probabilities $-c$ in the bad case and $c+\epsilon$ in the good case, where $c, \epsilon>0$ and $\epsilon$ can be seen as a measure

\footnotetext{
14 This corresponds to the standard setting that is used in the literature to illustrate the prospect theory argument, see e.g. Weber and Camerer (1998).
} 
of the attractiveness of the stock. As long as $\epsilon>0$, the loss-neutral investor buys the stock in $S=0$. If the good state realizes the investor has the choice between realizing his gain, which implies the certain pay off $c+\epsilon$, and continuing to hold the stock, which offers him the pay offs $\epsilon$ and $2(c+\epsilon)$. Since the investor is risk-averse in the gain domain he prefers the certain expected value of the lottery to the lottery itself, i.e. he prefers $c+\frac{3}{2} \epsilon$ to the stock.

However, selling the stock implies a sure payoff of $c+\epsilon$, which is smaller than the expected value of the risky asset. Therefore the investor's decision to sell the stock depends on his risk aversion, $\alpha$, and the attractiveness of the stock, $\epsilon$.

If the stock price declines, the investor has the choice between a sure loss of $-c$ and a lottery that yields $-2 c$ or $\epsilon$. Since the investor is risk-loving and the stock offers a positive payoff in the good state, the investor will continue to hold the stock.

We illustrate two different cases for $S=U$ in Figure 4. In the left panel we show the case where the investor sells the winning stock. This case arises for unattractive stocks with a low $\epsilon=\epsilon_{L}$. The setting is constructed such that the loss-neutral investor buys the stock in $S=0$. In $S=U$ the utility from realizing the gain $v\left(c+\epsilon_{L}\right)$ is higher than the utility from holding the stock, $\frac{1}{2}\left(v\left(2 c+2 \epsilon_{L}\right)+v\left(\epsilon_{L}\right)\right)$, marked in the Figure with a filled circle. Therefore the disposition effect occurs. In the right panel we depict the case where the investor keeps on holding the attractive stock, $\epsilon=\epsilon_{H}$. The utility from owning the stock, $\frac{1}{2}\left(v\left(2 c+2 \epsilon_{L}\right)+v\left(\epsilon_{L}\right)\right)$, marked with a filled circle, exceeds the utility of the certain first period gain $v\left(c+\epsilon_{H}\right)$. Therefore, in this case the ex-ante disposition effect does not occur.

As shown in Figure 4, there are certain cases, where the S-shaped value function can indeed induce the ex-ante disposition effect for loss-neutral investors. However, as our numeric result from Section 3.1 indicate, the ex-ante disposition effect occurs for the loss-neutral investor only in about $9 \%$ of the cases. So in general even a loss-neutral investor is not prone to the disposition effect.

\subsection{Robustness}

Other numerical analyzes for different parameter values confirm that the ex-post conditions are satisfied more often than conditions for the ex-ante disposition effect and that the differences can be quite substantial. 

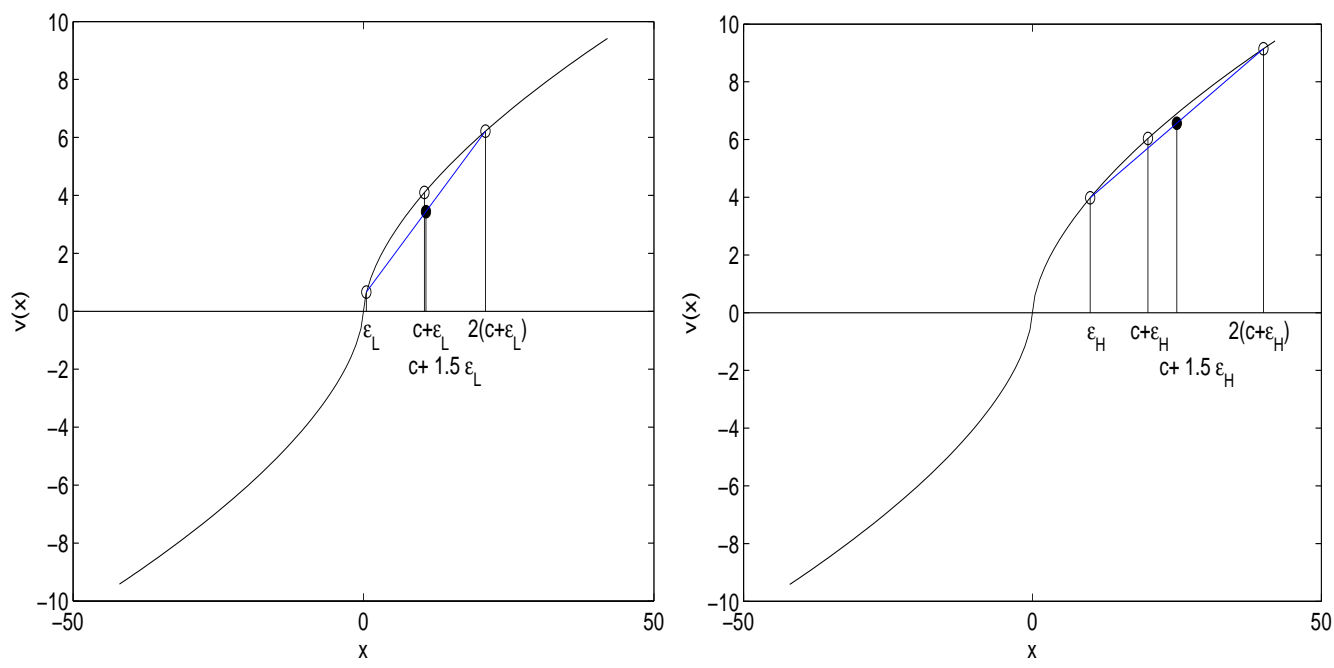

Figure 4: Value functions for Loss-Neutral Investors in $S=U$. In the left panel we illustrate the case where the loss-neutral investor sells the winning stock and hence the disposition effect occurs. The following parameter values are used: $\alpha=0.6, \beta=1, \gamma=1, c=10, \epsilon_{L}=0.5, p=0.5$. In the right panel we illustrate the case where the investor keeps on holding the attractive stock, $\epsilon_{H}=10$, and therefore the disposition effect does not occur.

In particular, Figure 5 shows that neither probabilities different to 0.5 nor probability weighting can explain the ex-ante disposition effect while for some combinations the ex-post disposition effect occurs.

Similar results are obtained for other forms of value functions, e.g. the piece-wise exponential function. For preference parameter values that best approximate the empirical evidence found by Tversky and Kahneman $(1992)^{15}$ and market parameters as used above, we found that the ex-post disposition effect occurs in about $59 \%$ of the cases, whereas the ex-ante disposition effect occurs in less than $0.5 \%$. These values correspond to the results presented in this article.

Moreover, introducing editing rules of prospect theory, such as e.g. segregation, does not change the results substantially. For the parameter values used above, we found that the ex-post disposition effect occurs in about $65 \%$

\footnotetext{
${ }^{15}$ For a discussion and the concrete parameter values, we refer the reader to DeGiorgi, Hens, and Levy (2004).
} 

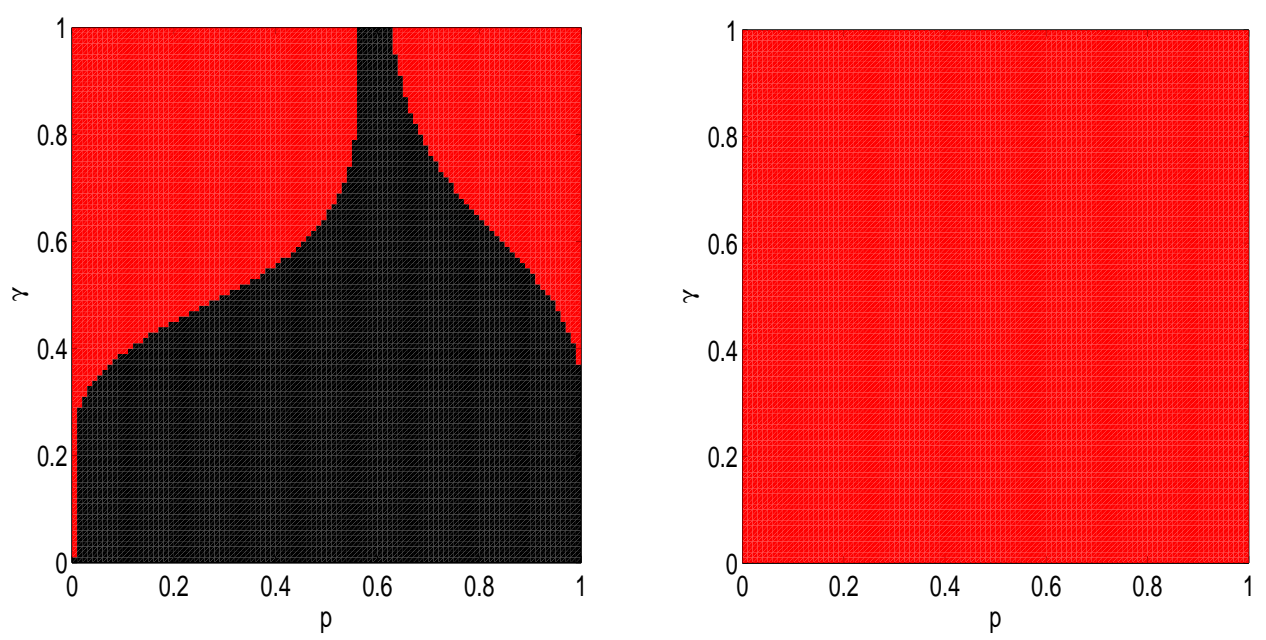

Figure 5: The first (second) graph shows the occurrence of the Ex-Post (exante) disposition effect. While changing the probability $p$ of the "up" state and also the degree of the probability weighting $\gamma$, we kept the other value function parameters (the risk aversion $\alpha$ and the loss aversion $\beta$ ) fixed at the level suggested by Tversky and Kahneman (1992). The returns are fixed as before to $R_{U}=1.33$ and $R_{D}=0.77$. The parameter combinations, where the disposition effect occurs, are marked in black. 
of the cases and the ex-ante disposition effect in less than 0.5\%. Furthermore, requiring dynamic instead of myopic optimization makes the risky asset more attractive in the first period, because one anticipates to react optimally to the future course of events. However, whenever the agent prefers to invest in the risky asset in the first period, he prefers to keep it after its price appreciates. In this case, the ex-ante disposition effect also occurs in less than $0.5 \%$ of the parameter combinations. Finally, assuming that the parameters are uniformly distributed over the respective intervals does not alter our results.

We also check the robustness of our result for the case where any fraction of wealth can be invested in the risky asset. We assess the occurrence of the disposition effect for different $R_{f}$, where $R_{f}=\{1.1,1.05,1.03,1.01,1.005\}$. The returns of the risky asset range from 0 to 1 in the bad state and from $R_{f}$ to $1+R_{f}$ in the good state. In all these cases the disposition effect never occurs.

These parameter values cover a wide range of possible return combinations and therefore include realistic and plausible parameter combinations. For plausible monthly parameters, e.g. $R_{f}=1.005$ and $R_{U}=1.04$ and $R_{D}=0.98$, the investor chooses to allocate in the first period $17 \%$ of his wealth in the risky asset, $55 \%$ in the up state and $20 \%$ in the down state. Therefore he is not prone to the disposition effect.

We do also perform our analysis for cumulative prospect theory (CPT). ${ }^{16}$ For this specification the disposition effect never occurs. Hence, our finding that prospect theory cannot explain the disposition effect is robust to such modification of prospect theory.

Moreover, we perform analyzes for the occurrence of the disposition effect, given that it is optimal for the individual to invest in the risky asset in $t=0$. This "conditional disposition effect" does not occur.

Finally we perform an analysis for an intertemporal optimization setting where, as in Barberis and Xiong (2009), the investor measures relative to the reference point $R P_{t}=W_{t-1} R_{f}$ and assume that he does weight the outcomes with their objective probability. Again, our finding that prospect theory cannot explain the disposition effect is confirmed.

Hence, we have shown that various approaches based on prospect the-

\footnotetext{
${ }^{16}$ For simplicity, we use in our simulations a slightly different definition for the CPT functional than in Tversky and Kahneman (1992). We define it in the following way: for a lottery $A$ with $n$ outcomes $x_{1}, x_{2}, \ldots, x_{n}$ and the probabilities $p_{1}, \ldots, p_{n}$, where $x_{1}<x_{2}<$ $\ldots<x_{n}$ and $\sum_{i=1}^{n} p_{i}=1$, we define $C P T(A)=\sum_{i=1}^{n}\left(w\left(F_{i}\right)-w\left(F_{i-1}\right)\right) v\left(x_{i}\right)$, where $v$ is the value function, $w$ the probability weighting function, $F_{0}:=0$ and $F_{i}:=\sum_{j=1}^{i} p_{j}$.
} 
ory have difficulty to model the disposition effect. Besides a large variety of plausible parameter values, we allow in the extensions of our model for different forms of value functions, reference points, editing, different forms of probability weighing and for dynamic optimization. None of them can help to explain the disposition effect. ${ }^{17}$

\subsection{Alternative Explanation}

Our results suggest that, in order to explain the disposition effect, one must depart from the traditional paradigm in a more radical way than just replacing the von Neumann-Morgenstern utility function in the expected utility paradigm with the value function of prospect theory. ${ }^{18}$

We conclude this discussion by providing an alternative explanation for the disposition effect based on backward looking behavior. Suppose the investor, after observing the outcome of an investment decision, decides in such a way that he rationalizes his past investment decisions. If the past investment decision is successful, the agent realizes his gain. This yields utility because he feels successful. If he incurs a loss, he keeps the asset. ${ }^{19}$ One could model such behavior using two mental accounts, one for realized gains and losses and the other for paper gains and losses. Clearly, in such a model, the positions in the paper account have less weight than the positions in the realized account: paper losses hurt less than realized losses, and realized gains provide more utility than paper gains. However, such behavior is not future oriented, because the resulting asset allocation may not be optimal in the future. This explanation corresponds to the story told by Gross (1982), page 150: Investors who accept losses can no longer prattle to their loved ones, "Honey, it's only a paper loss." The recent paper by Barberis and Xiong (2008) has developed this idea rigorously.

\footnotetext{
${ }^{17}$ The fact, that prospect theory does not generally predict disposition behavior, does not necessarily imply that it predicts that investors are prone to the house money effect. Thaler and Johnson (1990) observe in their experiments that subjects take more (less) risk after a gain (loss), and refer to this observation as the house money effect.

18 The key to the standard prospect theory explanation for the disposition effect is the S-shaped value function. Recently, experimental evidence has been accumulated against the S-shape value function (see e.g. Levy and Levy (2002)). This indirectly supports our argument that it must be something other than the S-shape value function that drives the disposition effect.

${ }^{19}$ There is evidence that emotions may have important role in explaining disposition behavior, see e.g. Summers and Duxbury (2007).
} 


\section{Conclusions}

In the literature, the disposition effect is explained by two main features of prospect theory, namely that decision-makers frame their choices in terms of potential gains and losses and that they maximize an S-shaped value function, which is concave for gains and convex for losses. The argument is often made without considering loss aversion. We show that the assumption of no loss aversion favors the occurrence of the disposition effect. Furthermore, in the standard argument, it is generally assumed that the investor has bought the risky stock in the first place. Therefore, the issue of whether the investor really will decide in this way is ignored. This implies that the standard argument is, in fact, an ex-post argument. After analyzing ex-post disposition behavior, we focus on a more complete definition of disposition behavior, the ex-ante disposition effect, where, besides requiring investors to sell winners and to hold losers, we require them explicitly to buy the stock in the first period. Our model shows that ex-ante disposition behavior occurs only for very restricted parameter values. In general, the model predicts that those investors who sell winning stocks too early and hold losing stocks too long would not, in the first place, have invested in stocks. We conclude that prospect theory can indeed explain ex-post disposition behavior, but not ex-ante disposition behavior.

In future research the model can be extended beyond the binomial case and towards multiple risky assets. However, we belief that our main conclusion is robust to these extensions. Possible alternative explanations for the disposition effect could include mental accounting combined with backward looking behavior.

\section{A Appendix}

\section{A.1 Proof of Proposition 1}

1. We analyze the two conditions in $t=1$ for the parameter combination $\gamma=1$ and $\alpha=0$. In the first case, where $R_{f} R_{D}>1$ and the second case, where $R_{U} R_{D}>1$ and $R_{f} R_{D}<1$, the condition to sell the asset 
after a gain yields

$$
p+(1-p) \leq 1
$$

which is satisfied for all $0<p<1$. The condition for the investor to prefer the risky asset in $S=D$ in the first case yields

$$
-(1-p) \beta \geq 1-p
$$

which yields a contradiction for all $\beta \geq 1$ and $0<p<1$, so that no ex-post disposition effect occurs. In the second case, the condition yields

$$
p \geq-p \beta
$$

which is satisfied for all $\beta \geq 1$ and $0<p<1$, so that the ex-post disposition effect does arise. In the third case, where $R_{U} R_{D}<1$, the condition to sell the winning stock yields

$$
-(1-p) \beta \leq 1-p
$$

which is satisfied for all $\beta \geq 1$ and $0<p<1$, and the condition to hold a losing stock yields

$$
p+(1-p) \leq 1
$$

which is satisfied for all $0<p<1$, so that the ex-post disposition effect does arise.

Note that, in the above inequalities, the assumption about the investor's behavior, when he is indifferent, is crucial. In the case of inequalities being strict, the ex-post disposition effect does not occur.

2. In the first case, where $R_{f} R_{D}>1$, the ex-post condition is satisfied whenever

$$
\begin{aligned}
& \phi_{1} \geq p \geq \phi_{2} \\
& \text { where } \phi_{1}=\frac{R_{f}-R_{D}}{R_{U}-R_{D}}, \\
& \phi_{2}=\frac{R_{f} R_{D}-1+\beta\left(1-R_{D} R_{D}\right)}{R_{U} R_{D}-1+\beta\left(1-R_{D} R_{D}\right)} .
\end{aligned}
$$


In the absence of arbitrage, and for all $\beta>1$, it follows that $\phi_{2}>\phi_{1}$, so that this condition is never satisfied. ${ }^{20}$ In the case where $R_{U} R_{D}>1$ and $R_{f} R_{D}<1$, the ex-post disposition effect arises whenever

$$
\begin{aligned}
& \phi_{1} \geq p \geq \phi_{3} \\
& \quad \text { where } \quad \phi_{3}=\frac{\beta R_{D}\left(R_{f}-R_{D}\right)}{R_{U} R_{D}-1+\beta\left(1-R_{D} R_{D}\right)} .
\end{aligned}
$$

Note that, in the absence of arbitrage, and for all $\beta>1$, it follows that $\phi_{3}>\phi_{1}$, so that this condition is never satisfied. In the case where $R_{U} R_{D}<1$, the ex-post disposition effect arises whenever

$$
\begin{aligned}
& \phi_{4} \geq p \geq \phi_{1} \\
& \quad \text { where } \quad \phi_{4}=\frac{R_{U} R_{f}-1+\beta\left(1-R_{U} R_{D}\right)}{R_{U} R_{U}-1+\beta\left(1-R_{U} R_{D}\right)} .
\end{aligned}
$$

Note that, in the absence of arbitrage, and for all $\beta>1, \phi_{3}>\phi_{1}$.

3. In the first case, where $R_{f} R_{D}>1$, the agent prefers to invest his wealth in the risk-free asset in $S=U$, if

$$
w(p)+w(1-p) \leq 1,
$$

which is true for all $0<\gamma<1$ and $0<p<1$. The condition to prefer to invest in the risky asset in $S=D$ yields

$$
-w(1-p) \beta \geq 1-w(p),
$$

which yields a contradiction for all $\beta \geq 1$ and $0<w(x)<1$, so that no ex-post disposition effect occurs. In the second case, where $R_{U} R_{D}>1$ and $R_{f} R_{D}<1$, the agent prefers to invest his wealth in the risk-free asset in $S=U$, if

$$
w(p)+w(1-p) \leq 1,
$$

which is true for all $0<\gamma<1$ and $0<p<1$. The condition to prefer to invest in the risky asset, in $S=D$, yields

$$
w(p) \geq(w(1-p)-1) \beta,
$$

\footnotetext{
${ }^{20}$ Note that, for an investor who is not loss-averse, i.e. $\beta=1, \phi_{2}=\phi_{1}$ for all parameters. Therefore the investor is prone to the ex-post disposition effect in the special case where $p=\phi_{2}=\phi_{1}$, that is where the objective probability equals the Martingale probability.
} 
which is satisfied for all $\beta \geq 1$ and $0<w(x)<1$, so that the expost disposition effect occurs in this case. In the third case, where $R_{U} R_{D}<1$, the agent prefers to invest his wealth in the risk-free asset, in $S=U$, if

$$
-w(1-p) \beta \leq 1-w(p)
$$

which is true for all $\beta \geq 1$ and $0<w(x)<1$. The condition to prefer to invest in the risky asset, in $S=D$, yields

$$
w(p)+w(1-p) \leq 1
$$

which is true for all $0<\gamma<1$ and $0<p<1$, so that the investor behaves from an ex-post perspective as a disposition investor whenever the investor makes a sure loss investing in the risk-free asset in $S=D$.

\section{A.2 Proof of Proposition 2}

1. For the parameter combination $\gamma=1$ and $\alpha=0$, the condition to invest in the risky asset in $t=0$ is:

$$
-(1-p) \beta \geq 1-p
$$

which is a contradiction for all $0<p<1$ and $\beta \geq 1$, since the left hand side is negative. Therefore the fairly risk-averse investor, who weights outcomes with their objective probability, never invests in the risky asset in $t=0$, implying that he cannot be prone to the disposition effect.

2. For the parameter combination $\gamma=1$ and $\alpha=1$ in the first case, where $R_{f} R_{D}>1$, the condition that the investor buys the stock in the first period and sells it after a gain yields

$$
\begin{array}{r}
p\left(R_{U}-1\right)-(1-p) \beta\left(1-R_{D}\right)-R_{f}+1 \geq 0, \\
p\left(R_{U} R_{U}-1\right)+(1-p)\left(R_{U} R_{D}-1\right)-R_{U} R_{f}+1 \leq 0 .
\end{array}
$$


These conditions cannot be satisfied simultaneously, since combining them yields $(1-p)(\beta-1)\left(R_{D}-1\right) \geq 0$, which is a contradiction for all $0<p<1, \beta>1$ and $R_{D}<1^{21}$. In the case where $R_{U} R_{D}>1$ and $R_{f} R_{D}<1$, the conditions for the investor to buy the risky asset in $t=0$, and to sell it after a gain, are the same as in the case where $R_{U} R_{D}>1$ and $R_{f} R_{D}>1$.

In the case where $R_{U} R_{D}<1$ and $R_{f} R_{D}<1$, the condition that the investor buys the stock in the first period and sells it after a gain yields $(1-p)(\beta-1) \leq 0$, which is a contradiction for all $0<p<1$ and $\beta>1$.

3. For the parameter combination $0<\gamma<1$ and $\alpha=0$, the condition for $t=0$ is:

$$
-w(1-p) \beta \geq 1-w(p)
$$

which is a contradiction for all $0<w(p)<1$ and $\beta \geq 1$, so that the fairly risk-averse investor never invests in the risky asset in $t=0$, implying that he is not prone to the disposition effect.

\section{References}

Barberis, N., And T. SAntos (2001): "Mental Accounting, Loss Aversion, and Individual Stock Returns," Journal of Finance, 56, 1247-92.

Barberis, N., AND W. XIONG (2008): "Realization Utility," Yale and Princeton University.

(2009): "What Drives the Disposition Effect? An Analysis of a Long-standing Preference-based Explanation," Journal of Finance, 64 (2), $751-784$.

Benartzi, S., and R. H. Thaler (1995): "Myopic loss aversion and the equity premium puzzle," Quarterly Journal of Economics, 110, 73-92.

\footnotetext{
${ }^{21}$ Note that an investor who is not loss-averse, i.e. $\beta=1$, would buy the stock in the first period and sell it after a gain.
} 
Berkelaar, A. B., R. Kouwenberg, and T. Post (2004): "Optimal Portfolio Choice under Loss Aversion," Review of Economics and Statistics, 86, 973-987.

DeGiorgi, E., T. Hens, and H. Levy (2004): "Existence of CAPM Equilibria with Prospect Theory Preferences," NCCR-Finrisk Working Paper No. 85, University of Zurich.

Fama, E., and K. R. French (1993): "Common Risk Factors in the Returns on Stock and Bonds," Journal of Financial Economics, 33, 3-56.

Feng, L., And M. S. Seasholes (2005): "Do Investor Sophistication and Trading Experience Eliminate Behavioral Biases in Financial Markets?," Review of Finance, 9, 305-51.

Gomes, F. J. (2005): "Portfolio Choice and Trading Volume with LossAverse Investors," Journal of Business, 78, 675-706.

Grinblatt, M., And M. Keloharju (2000): "The Investment Behavior and Performance of Various Investor Types: A Study of Finland's Unique Data Set," Journal of Financial Economics, 55, 43-67.

\section{9-616.}

Gross, L. (1982): The Art of Selling Intangibles: How to Make Your Million(\$) by Investing Others People's Money. New York Institute of Finance.

Heath, C., S. Huddart, and M. Lang (1999): "Psychological Factors and Stock Option Exercise," Quarterly Journal of Economics, 114, 601627.

Kahneman, D., And A. Tversky (1979): "Prospect Theory: An Analysis of Decision under Risk," Econometrica, 47, 263-291.

Kaustia, M. (2009): "Prospect Theory and the Disposition Effect," Journal of Financial and Quantitative Analysis, forthcoming.

Kyle, A. S., H. Ou-Yang, and W. Xiong (2003): "Prospect Theory and Liquidation Decisions," Journal of Economic Theory, Forthcoming. 
Levy, M., AND H. Levy (2002): "Prospect Theory: Much Ado about Nothing?," Management Science, 48, 1334-1349.

Locke, P. R., and S. C. Mann (2001): "Do Professional Traders Exhibit Loss Realization Aversion?," George Washington University - Department of Finance and Texas Christian University - M.J. Neeley School of Business Working Paper.

Merton, R. C. (1969): "Lifetime Portfolio Selection under Uncertainty: The Continuous-Time Case," Review of Economics and Statistics, 51, 247257.

Odean, T. (1998): "Are Investors Reluctant to Realize their Losses," Journal of Finance, 53, 1775-1798.

Ranguelova, E. (2002): "Disposition Effect and Firm Size: New Evidence on Individual Investor Trading Activity," Center for Mathematics and Computer Science (CWI), Harvard University.

Samuelson, P. A. (1969): "Lifetime Portfolio Selection by Dynamic Stochastic Programming," Review of Economics and Statistics, 51, 239246 .

Shefrin, H., and M. Statman (1985): "The Disposition to Sell Winners too Early and Ride Losers too Long: Theory and Evidence," Journal of Finance, 40, 777-790.

Shumway, T., And G. Wu (2007): "Does Disposition Drive Momentum?," Ross School of Business University of Michigan and University of Houston.

Summers, B., And D. Duxbury (2007): "Unraveling the Disposition Effect: The Role of Prospect Theory and Emotions," Available at SSRN: http://ssrn.com/abstract $=1026915$.

Thaler, R. H., And E. J. Johnson (1990): "Gambling with the House Money and Trying to Break Even: The Effects of Prior Outcomes on Risky Choice," Management Science, 6, 643-660.

Tversky, A., And D. Kahneman (1992): "Advances in prospect theory: cumulative representation of uncertainty," Journal of Risk and Uncertainty, 5, 297-323. 
Vlcek, M. (2005): "Portfolio Choice with Loss Aversion, Asymmetric Risk-Taking Behavior and Segregation of Riskless Opportunities," NCCRFinrisk Working Paper No. 284, University of Zurich.

Weber, M., and C. F. Camerer (1998): "The Disposition Effect in Securities Trading: An Experimental Analysis," Journal of Economic Behavior E Organization, 33, 167-184. 